\title{
Crystallographic Orientation Influence on Slip System Activation and Deformation Mechanisms in Waspaloy during in-situ Mechanical Loading
}

James Parkin ${ }^{1}$ and Soran Birosca ${ }^{2}$

${ }^{1}$ Institute of Structural Materials, College of Engineering, Swansea University, Bay Campus, Swansea SA1 8EN, UK.

${ }^{2}$ School of Mechanical and Design Engineering, Faculty of Technology, University of Portsmouth, Anglesea Building, Anglesea Road, Portsmouth PO1 3DJ, UK

\begin{abstract}
The deformation mechanism correlations with individual grain orientation, overall texture, grain boundary characteristics, dislocation accumulation and evolutions were investigated during in-situ room temperature tensile testing of a nickel-based superalloy, Waspaloy. During tensile testing, electron backscatter diffraction (EBSD) mappings, as well as electron microscopy images were acquired at increments of displacement to observe the exact deformation mechanics in different orientated grains during plastic deformation. Here, it is demonstrated that Cube $(001)<100>$ orientated grains were readily rotated and Copper $(112)<111>$ texture component area fraction increased during loading. It was also shown that Cube orientated grains behaved as "soft" grains and easily activated an available octahedral $(111)<1-10>$ slip system through simple shear mechanisms, allowing for easy dislocation movement and accumulation within the grain. On the contrary, Brass $(011)<211>$ grains acted as "hard" and most stable orientation as they were not favourably orientated for octahedral $(111)<1-10>$ slip system activation. The response variations to external loading from different orientated grains created a high strain incompatibility between
\end{abstract}


neighbouring grains causing high GND density within the grains and along grain boundaries depending on the grain's orientation.

Keywords: Waspaloy, EBSD, Slip System, Deformation Mechanism, Texture

\section{Introduction}

Waspaloy, a wrought age-hardened nickel-based superalloy, is produced through the ingot metallurgy route. Waspaloy is then forged and followed by suitable heat treatments with an ageing phase conducted to produce an optimal microstructure to be used for turbine discs in gas turbine engines. During service, Waspaloy, used for turbine disc is subjected to high rotational stresses at elevated temperatures [1-2]. Hence Waspaloy requires high temperature capabilities. Properties including; high tensile strength, high hardness, good fatigue resistance and good corrosion resistance, notably to oxidation and maintaining these properties at high temperature [3][4][5][7]. Waspaloy has a maximum operating temperature for critical rotating components of $650^{\circ} \mathrm{C}$ and $870^{\circ} \mathrm{C}$ for non-critical components [4]. It owes its high strength properties to a bimodal distribution of gamma prime $\left(\gamma^{\prime}\right)$ particles resulting from additions of aluminium and titanium which demonstrates an ordered $\mathrm{L}_{2}$ crystal structure being coherently embedded within the nickel-rich face-centred cubic (FCC) gamma $(\gamma)$ matrix [3][6][8-10]. Further strength is gained with additions of elements such as; cobalt, chromium and molybdenum through solid solution strengthening as well as $\mathrm{M}_{23} \mathrm{C}_{6}$ carbides residing on grain boundaries to reduce grain boundary sliding at elevated temperatures [3][11][12][13]. The $\gamma^{\prime}$ precipitates are responsible for further strengthening via providing obstacles for the dislocation movement [3][14][16]. Secondary $\gamma^{\prime}$ in Waspaloy exists as spherical particles of which are coherently embedded within the FCC $y$ matrix helping to impede dislocation motion. This act of impeding dislocations improves mechanical properties, especially at elevated temperatures [15-17]. 
Overall crystallographic texture of Waspaloy can influence the mechanical properties of the alloy during high-temperature applications. The crystallographic texture of an alloy is more likely to be inherited from the manufacturing processes [18]. In general, nickel-based superalloy demonstrates weak texture post materials processing. In a material with weak texture and a homogeneous microstructure (homogeneous particle, second phase, grain size and shape distribution), the local texture (or individual grain orientation) can play a critical role during deformation [19]. These aspects are strongly correlated to the octahedral slip systems activation in different orientated grains. Within Waspaloys random texture exhibits certain texture components including; Cube $(001)<100>$, Goss $(011)<100>$, Brass $(011)<211>$, Copper $(112)<111>$ and $S(123)<634>$.

During plastic deformation of a polycrystalline alloy, strain heterogeneities develop at the micro and macro scale. This is manifested by slip trace observation at the micro-scale where the slip acts as highway for dislocation motion. During the work hardening of a Waspaloy, dislocations are generated, moved along slip planes, trapped and entangled at interfaces such as grain boundaries or $\gamma^{\prime}$ precipitates interfaces. This type of dislocation is known as statistically stored dislocations (SSDs). Whereas geometrically necessary dislocations (GNDs) have a geometric effect on the atomic and micro scales due to crystal lattice curvature. Furthermore, orientation gradients within individual grains will become prominent from originally homogenous grains during deformation. Here, GNDs can accommodate these local orientation differences which have a geometric effect on the heterogeneous plastic strain [11]. However, the overall texture of Waspaloy can play a key role in the anisotropy of the properties. For instance, Cube texture component is considered as "soft" grains, demonstrating high Schmid factors and low strain hardening $[11,19]$. On other hand, Brass texture grains can be considered "hard" grains. These grains are orientated to the loading direction such that a low Schmid factor is usually observed [11,19]. This, in turn, results in Brass grains having to re-orientate during plastic deformation to activate any of the available octahedral slip systems. 
This results in strain incompatibilities between the grains leading to high strain hardening in the alloy [19].

In recent years, in-situ testing on small-scale samples has allowed for tracking the deformation mechanisms on surface grains. Coupled with a scanning electron microscopy (SEM), electron imaging and orientation information obtained though electron backscatter diffraction patterns (EBSP) allowing for vast amounts of information to be acquired at different stages of plastic deformation. This allows the evolution of plastic deformation and local strains to be quantified as a function of grain orientations [20-23]. The objective of the current study was to investigate the effects and evolution of local texture on the deformation mechanisms during room temperature insitu tensile testing. Furthermore, tracking the effects of hard (Brass) and soft (Cube) grain texture component on the mechanics of deformation was investigated. Here, the real time observation and tracking the texture components changes were achieved through the application of electron backscatter diffraction (EBSD) system during in-situ testing.

\section{Experimental Methods}

\subsection{Material Used}

The experimental alloy used in this study was a $\gamma^{\prime}$ strengthened nickel-based superalloy; Waspaloy, which was provided by Rolls-Royce plc. The chemical composition of the alloy is shown in Table.1. The experimental Waspaloy was taken from a forged disc which was produced through the ingot metallurgy route. The heat treatment for the alloy was as follows; $995-1040{ }^{\circ} \mathrm{C}$ for $4 \mathrm{~h}(\mathrm{~h})$, air-cooled (AC), followed by a stabilisation period at $845^{\circ} \mathrm{C}$ for $4 \mathrm{~h} / \mathrm{AC}$, and then aged at $760^{\circ} \mathrm{C} / 16 \mathrm{~h} / \mathrm{AC}$.

\subsection{Sample Preparation}


Flat dog-bone samples were prepared from the as-received discs using electrical discharge machining (EDM). The dimensions of the produced test samples were as follows; a total sample length $(L)=64 \mathrm{~mm}$, a gauge length $(G L)=12 \mathrm{~mm}$, a gauge width $(W)$ and thickness $(T)$ of $3.2 \mathrm{~mm}$ and $1 \mathrm{~mm}$, respectively, see Figure 1a. Prior to in-situ tensile testing, the samples were prepared for SEM and EBSD analysis using standard grinding and polishing routes. The samples were finely polished on a vibratory polisher using $0.02 \mu \mathrm{m}$ colloidal silica for 10 minutes to produce a mirror-like finish on one side of the gauge for fast and good quality EBSD data acquisition.

\subsection{Characterisation Techniques}

Prior to in-situ testing, the samples were characterised using EBSD mapping and SEM imaging techniques including secondary electron (SE) and backscattered electrons (BSE) to observe the original sample microstructure and macrotexture of the alloy. To analyse the $\gamma^{\prime}$ content in the alloy, the $\gamma$ matrix had to be etched away. This was achieved using an electric etchant solution of phosphoric acid to reveal the $\gamma^{\prime}$ precipitates. Images were taken using the Joel field emission gun (FEG-SEM) mainly under BSE conditions. ImageJ software was used to characterise size and area fraction of secondary $\gamma^{\prime}$ content in the alloy investigated here. Grain size, shape and morphology were characterised using EBSD and SE images using the linear intercept method. Twin boundaries of $\Sigma 3$ orientation were not included in the grain size calculations.

\subsection{In-situ Tensile Test Set-up}

The in-situ tests were carried out using a linear, screw-driven load frame (Swift Instruments SWF 5000 tensile stage) inside an SEM (Hitachi SU3500 SEM), see Figure 1b. The in-situ stage used in the current study has a load capacity of $5000 \mathrm{~N}$ with an accuracy of $\pm 0.2 \%$. The in-situ stage is controlled using an interface system that connects the stage using pass-through port connections inside the SEM chamber. The "Qaudature" software was used to input the testing parameters and data 
recording. In-situ tests were performed by clamping the Waspaloy specimen into the SWF in-situ testing frame by wedge grips on each side. The main difficulty when performing in-situ tensile tests was determining the precise material strain (\%). This is due to the small sample $<12 \mathrm{~mm}$ gauge length, and a regular extensometer was too large to be used in such a condition. Intermittent room temperature (RT) tensile tests were performed under vacuum within the SEM using an un-notched Waspaloy specimen. Crosshead displacements (CHD) were taken to $0 \mu \mathrm{m}, 600 \mu \mathrm{m}, 1200 \mu \mathrm{m}, 1800 \mu \mathrm{m}$, $2400 \mu \mathrm{m}$ and $3000 \mu \mathrm{m}$. A displacement rate of $200 \mu \mathrm{m} /$ minute was used. Material strain was calculated from crosshead displacement measurements with relative crosshead displacement strains (CHD\%) being $0 \%, 5.2 \%, 10.4 \%, 15.7 \%, 20.9 \%$ and $26.2 \%$ at a rate of $0.027 \mathrm{~s}^{-1}$. Once the sample was at the intermittent displacements a holding period of 15 minutes was applied to allow for EBSD orientation data to be acquired. A step size of $1 \mu \mathrm{m}$ was used during EBSD mapping.

\section{Results and Discussion}

As shown in Figure $2 \mathrm{a}$, the $\gamma$ grains have an equiaxed shape with a grain size of $60 \mu \mathrm{m} \pm 10 \mu \mathrm{m}$. Figure $2 \mathrm{~b}$ shows secondary and tertiary $\gamma^{\prime}$ within the $\gamma$ matrix. Both secondary and tertiary $\gamma^{\prime}$ was found to have spherical shape precipitates. It is calculated that secondary $\gamma^{\prime}$ have an average diameter of $55 \mathrm{~nm}$ with a volume fraction of $23 \%$. As expected, the $\gamma$ grain boundaries were decorated by carbides. This is related to the high C content in Waspaloy. Figure 3 shows the chemical mapping via energy-dispersive X-ray spectroscopy (EDX) in the vicinity of the grain boundaries which confirmed the presence of $\mathrm{C}_{23} \mathrm{C}_{6}$ carbides.

\subsection{Waspaloy Performance during in-situ Tensile Test}

Stress-strain data was calculated from the crosshead displacement measurements and is presented in Figure 4. It appeared from the mechanical testing data that during the hold period for EBSD acquisition in the elastic region, the load dropped by $8 \pm 1 \mathrm{~N}$ whereas in the plastic region the load 
dropped by $30 \pm 5 \mathrm{~N}$. This is related to the fact that the sample exhibited stress relaxation during the holding period of 15 minutes for EBSD data acquisition. The first EBSD map was taken at a preload stress of $125 \mathrm{MPa}$ followed by scans performed at crosshead displacement increments of $600 \mu \mathrm{m}$ with a final EBSD map was conducted at $2400 \mu \mathrm{m}$. It should be noted that the acquired Waspaloy strain-strain data via in-situ testing was comparable with available standard laboratory tensile testing machine data with 870 MPa yield stress, 1140 MPa UTS, 201 GPa Young Modulus and $25 \%$ elongation.

\subsection{Microstructure Evolution and its Correlation with Deformation Mechanism during in-situ}

\section{Tensile Test}

Figure $5\left(a_{1}-a_{5}\right)$ shows the forward scattered electrons (FSD) images of Waspaloy at increasing strain. Images in $1_{\mathrm{a}-\mathrm{e}}$, shows the pre-loading microstructure of the Waspaloy. As shown in image $2_{\mathrm{a}}$, no slip traces were observed at $600 \mu \mathrm{m}$ crosshead displacement (5.2\% strain). However, the slip traces appeared in most of the grains after $1200 \mu \mathrm{m},(10.4 \%)$, see Figure $5 \mathrm{a}_{3-5}$. It was evident from Figure 4 that at crosshead displacement strain $10.4 \%$ the Waspaloy sample is in the plastic deformation region where the material yield stress was calculated to be $870 \mathrm{MPa}$. It is assumed therefore that the octahedral slip systems were activated somewhere between $600 \mu \mathrm{m}$ and $1200 \mu \mathrm{m}(5.2$ and 10.4\%) (827 and $1015 \mathrm{MPa}$ ). It should be mentioned that during live (real time) observation of the test it was clear that at approximately $700 \mu \mathrm{m}$ displacement $(6.1 \%$ - $893 \mathrm{MPa})$ slip systems began sudden revelation simultaneously as the material deformed plastically. As the tensile test continues, the plastic deformation and grain shape distortion became more visible when the crosshead displacement reached $1800 \mu \mathrm{m}(15.7 \%-1061 \mathrm{MPa})$ and thereafter, see Figure 5a 4 -5. The topographical changes on the sample surface were visible after $1200 \mu \mathrm{m}$ displacement and some grains protruded out from the sample surface. Some orientated grains shrank or elongated to accommodate the externally applied loads, see Figure $5\left(a_{3}-a_{5}\right)$. This protrusion of the grains affected 
the quality of the EBSD scans in the later stages of deformation as some areas were now not optimally aligned to $70^{\circ}$ to the electron beam. Figure $5\left(b_{1}-b_{5}\right)$ shows the associated $(111)<1-10>/ /$ $\mathrm{x}$ Schmid factor (where $\mathrm{x}$ is the loading direction). The overall Schmid factor is increased as some oriented grains rotated to accommodate the applied stress to activate any of the octahedral slip systems. The grains with the highest Schmid factor (red) find it easy to activate an available slip system as they are preferentially oriented for $(110)<1-10>$ slip system activation. These grains were "soft" grains and only a single slip trace was observed to be activated in most cases.

Figure $5\left(c_{1}-c_{5}\right)$ shows the grain internal strain calculated by Channel $5 \mathrm{HKL}$ software. It appears that the values of grain internal strain are decreased and increased depending on the crystallographic orientation of the individual grains. This was mainly due to the grain orientation and strain incompatibility with neighbouring grains as it will be discussed in the next section. Figure $5\left(d_{1}-d_{5}\right)$ shows the local misorientation within the grains which indicate local strain accumulation. It is clear from the figure that the highest misorientation values were observed in the vicinity of high angle grain boundaries. However, "hard" grains, i.e, low Schmid factor that are difficult to activate any octahedral slip system, see Figure $5 a-b$, showed high local misorientation values within the centre of the grains, see Figure $5 \mathrm{~d}$. This experimental observation agrees with [11] and reflected perfectly in GND maps in Figure $5\left(\mathrm{e}_{1}-\mathrm{e}_{5}\right)$. It seems that the crystallographic grain orientation played a vital role in GND accumulation and its distribution. As theorised in $[11,19]$, for the soft grain to deform plastically the dislocations, including GND, would generate on (111) plane as this plane is perfectly aligned for $(110)<1-10>$ slip system activation. This condition facilitates simple shear condition, consequently, these high Schmid factor soft grains yield easily and plastically deform without need for reorientation. The generated GND continue to move until they reach a grain boundary as there is no obstacle to impede their movements. Considering the soft grain orientation and their high Schmid factor, these grains expected to shear promptly on (111) plane. However, the GNDs face a 
pronounced obstacle when reaching the grain boundaries and thus the GNDs will accumulate greatly near the grain boundaries, see Figure $5\left(e_{1}-e_{5}\right)$. This explains low GND density in the centre of most of the soft grains in the same figure. In hard grains, there is not any particular slip system favourably aligned for easy octahedral slip system activation. Thus, the hard grain tends to rotate to activate any available slip system including Cubic $(100)<110>$ slip systems. This grain rotation (reorientation) occurs during deformation to accommodate the externally imposed load. This will lead to further GND generation on multi-active and non-active slip planes within the hard grains. It appears that the hard grain resists the rotation through accommodating further GND. This leads to large GND and strain accumulations in the centre of hard grains.

\subsection{Waspaloy Texture Evolution during in-situ Tensile Loading}

Figure 6 shows highlighted individual texture components in Waspaloy during the in-situ tensile test. Figures $7 \mathrm{a}$ and $7 \mathrm{~b}$ show the individual texture component evolution at incremental strain and the changes in the texture component area fractions during in-situ tensile test, respectively. The crystallographic textures that are examined during the tensile test were; Cube $(001)<100>(\phi 1, \phi 2$, $\phi 3,0,0,0)$, Goss $(110)<100>(\phi 1, \phi 2, \phi 3,0,45,90)$, Brass $(011)<211>(\phi 1, \phi 2, \phi 3,35,45,90)$, Copper $(112)<111>(\phi 1, \phi 2, \phi 3,90,35,45)$ and $S(123)<634>(\phi 1, \phi 2, \phi 3,59,37,63)$. It is evident from Figure $6\left(a_{1}-a_{5}\right)$, that Cube texture component area fraction within the scanned area was decreased by $1.751 \%$, see also Figures 7a-b. A slight increase in Goss texture component was observed, see Figures $6\left(b_{1}-b_{5}\right)$ and 7a-b. Meanwhile, Brass texture component was found to be increased with plastic deformation, Figures $6\left(c_{1}-c_{5}\right)$. Copper texture component, on the other hand, was observed to be increasing on the expense of S texture component, see Figures $6\left(d_{1}-d_{5}\right)$ and $7 a-$ b, i.e., $S$ decreased, see Figure $6\left(\mathrm{e}_{1}-\mathrm{e}_{5}\right)$. Table 2 shows the calculated individual texture component area fraction and their development during in-situ tensile test at room temperature of Waspaloy. 
It is interesting to note that Goss $(011)<100>$ oriented grains were semi-stable though deformation stages but slightly changed by $1 \%$ at $2400 \mu \mathrm{m}$. Both Goss and Cube components are favourably oriented for slip system activation, i.e., high Schmid factor, and as stated in the previous section the dislocation can easily move on (111) slip plane until reaching grain boundaries. The large GND accumulation in the vicinity of grain boundaries. This allowed sub-grains formation with slight orientation difference locally and readily rotated that caused the observed changes in the component's area fraction \%. However, this can go in different directions, either by increasing the area fraction as in the case of Goss texture component or decreasing area fraction as for the case of Cube, see Figures 6 and 7a-b. The subgrain formation due to GND accumulation is also reported in [11]. Moreover, Brass (011) <211> texture component also was stable in the early stages of plastic deformation, then increased between $1800 \mu \mathrm{m}$ and $2400 \mu \mathrm{m}(15.7 \%-20.8 \%)$. The Brass stability during deformation is also reported in literature $[19,22]$. This is due to low Schmid factor for such a hard grain and resisting crystal rotation under the applied stress. However, at the late stage of deformation, the hard grain eventually fragmented internally as reported in [19]. However, Copper $(112)<111>$ and S $(123)<634>$ were both changed in opposite directions from the early stage of plastic deformation. This is also an interesting observation as $\mathbf{S}$ texture component is usually considered to be a typical deformation texture component in literature [24]. This may be due to an increase of neighbourhood Copper and Brass texture component area fractions.

To validate the subgrain formation near the grain boundaries and hard and soft grains different response to the applied loading, the main fibre texture development and grain boundary characteristic mapping was presented in Figure 8. From the statistical analysis, it appeared that the area fraction of $<100>/ / \mathrm{X}$-axis and $<111>/ / \mathrm{X}$-axis fibres increased, and overall $<110>/ / \mathrm{X}$-axis fibre decreased with increasing deformation. See Figure $8\left(c_{1}-c_{5}\right)$ for $<100>/ / X,\left(d_{1}-d_{5}\right)$ for $<110>/ / X$ and $\left(e_{1}-e_{5}\right)$ for $<111>/ / X$. This is validated by the fact the hard grains on the $<111>$ fibre was the most 
stable orientation during deformation and resisted grain rotation until the very last stage of deformation. It was also observed that there were 2 or more $(111)<1-10>$ slip traces observed in hard grains on $<110>$ and $<100>$ fibres leading to significant orientation gradients in such grains and final fragmentation. This increase in orientation spread could accommodate further plastic strain before final fracture.

Figure $8\left(a_{1}-a_{5}\right),\left(b_{1}-b_{5}\right)$ shows the evolution of low angle grain boundaries (LAGB) $<10^{\circ}$ and high angle grain boundaries $(\mathrm{HAGB})>15^{\circ}$, respectively. As expected, the LAGBs increases with increasing deformation strain\%. This is due to subgrain formation as grains tend to rotate to further accommodate the plastic strain imposed by external loading. However, grain local rotation in the vicinity of the grain boundary is not necessary to be uniform in differently oriented grains due to neighbouring grain orientation and grain boundary characteristics as well as carbides pinning which influences sub-grain formation greatly. This mixed parameter of (i) the orientation of the grains, (ii) the orientation of neighbouring grain, (iii) grain boundary type and (vi) carbide presence on the grain boundary can change the subgrain formation conditions greatly. This agrees with $[11,25]$ and it will be further discussed in the next section. It should be emphasised here that the increase in LAGBs is also reflected in the decrease of HAGBs, see Figure $8\left(a_{1}-a_{5}\right)\left(b_{1}-b_{5}\right)$.

\subsection{Slip System Activation in Individual Oriented Grains}

Figure 9a-c shows the visible slip traces on the SEM image, IPF // ND and Schmid factor // X-Axis maps for Waspaloy at $10.4 \%$ CHD strain. Figure 9a shows the revealed slips within individual grains and overlaid with calculated slip traces from EBSD orientation data. The slip traces are calculated from EBSD raw data following $[11,26]$. It should be noted that the slip traces with highest Schmid factor is indicated with a red line. Followed by the second highest with a blue line and the lowest value represented with a black line. For example, in grain numbered 1, the four slip systems in FCC 
crystals are; (111), (11-1), (1-11) and (-111) with associated Schmid factors; $0.23,0.33,0.49$ and 0.46 , respectively. It appears that the (1-11) primary slip trace had the Schmid factor of 0.49 in grain 1. It appeared that the calculated slip trace aligns up well with the visible slip traces in the microstructure. It is important to emphasise here that there were no slip traces observed in grains 15 and 25 which indicate no slip system was activated in those grains. From the calculated slip traces, most of the grains with a single activated slip system had the highest associated Schmid factor, red coloured line. This was the case for grains 1-6, 10, 13 and 21-24, but not the case for grains 7, 9 and 20 in which the second-highest Schmid factor slip system was activated. There are some grains with double or triple $(111)<1-10>$ slip system activation as can be seen in grains 8,12 , $14,16-19$ and 26 . These grains were "hard" grains on $<110>$ and $<100>$ fibres leading to significant orientation gradients in such grains. This increase in orientation spread allows these grains to accommodate further plastic strain before the final fracture.

All 26 grains in the scanned area at the latest stage of deformation strain were analysed and summarised in Table 3. It is clear to see that the Brass $(011)<211>$ texture component grains (G2, G9, G19 and G24) have relatively low Schmid factors ranging from 0.35-0.4 and are activating two or more $(111)<1-10>$ slip systems to accommodate the deformation applied. This is due to the hard nature of Brass grains which are not favourably oriented for octahedral slip activation and must rotate to activate a possible slip system. This, in turn, imposes more strain incompatibilities to surrounding neighbouring grains. From the same table, it is clear the grains (G5 and G20) with Cube (001) $<100>$ texture component have relatively high Schmid factors, 0.43 and 0.46 respectively. Only one slip system was activated in those "soft" grains, allowing for simple shear and unrestricted dislocation motion to occur in the highest Schmid factor slip system. Furthermore, in the Copper $(112)<111>$ and $S(123)<634>$ texture components lying on the $<111>$ texture fibre, there was 2 or more slip system activated at this late stage of deformation. 


\subsection{The effect of Carbide and $\gamma^{\prime}$ on the Slip Transfer and Void Formations}

The nature of slip system activation within soft and hard grains was concluded in Section 3.4. Here we investigated the slip transfer between soft-soft and soft-hard neighbouring grains. Typical scenarios for such a condition were captured in Figure 10. For instance, Figures 10b-c is a magnified boundary area between a soft and hard grains in (a), whereas Figure 10d show a magnified boundary area in (a) between two soft grains. It was clear from Figure 10b, that the octahedral slips in the soft grain could not transfer to the neighbouring hard grain where the grain boundary was decorated with carbide precipitates. The carbide here acted as a real obstacle for the slip transfer between the grains. However, when the grain boundary was free from carbide, the slip was easily transfer to the neighbouring grains. It should be noted here, the figure in $10 \mathrm{~b}$ validates the fact that only one single slip was activated in the soft grain and 2-3 slips were activated in the hard grain. Moreover, the slip could easily transfer between 2 neighbouring grain where the boundary was relatively carbide free without any noticeable changes in the slip direction, see Figure $10 \mathrm{~d}$.

The effect of $\gamma^{\prime}$ on the slip transfer is investigated in Figure 11a-b. It is clear from the figure that the slip could easily encounter and cut through the $\gamma^{\prime}$ without any diversion. This was the case within the hard and soft grain as well as through the grain boundary, see Figure 11a. Furthermore, multi slip intersection in the hard grain (highlighted in Figure 11a) observed within the $\gamma^{\prime}$, indicating on the absence of any influence of $\gamma^{\prime}$ on slip transfer. Meanwhile, as shown in Figure $11 \mathrm{~b}$, the effective obstacle to slip transfer remained carbide presence on the grain boundary between the grains. In fact, the distortion of the areas in the vicinity of carbide rich grain boundary could inhibit the slip continuity and caused slip direction diversion as highlighted in Figure 11c. The effect of carbide was further signified at the triple junction between differently oriented grain as shown in Figure 11d. The significant constrain at the meeting point of 5 grains with different orientations, where slip 
transfer was difficult and in the presence of carbide caused void formation between them as shown in the same figure. It was evidence from this investigation that carbide in Waspaloy played a critical role in deformation mechanism in the local areas.

\subsection{The Technical Issues with in-situ Testing using SEM}

The present study demonstrates the feasibility of conducting in-situ tensile tests using SEM and EBSD imaging tools to understand the deformation mechanics within individual oriented grains. The correlation between localised deformation to microstructural features was performed via correlating the EBSD data i.e., grain morphology and orientation during increments of plastic deformation. Technical issues involved with in-situ EBSD testing are; (i) mapping of a heavily deformed sample during the deformation test leads to significant mis-indexed points due to dislocation and sub-grain generation as well as increased LAGB and orientation gradient within the grains. (ii) Obtaining sharp EBSD diffraction pattern was further complicated at the late stage of plastic deformation where strain incompatibilities between neighbouring grains increased and leading to change of grain morphology and grains protruding outwards on the sample surface, see Figure 5(a5 - e5). (iii) A further issue is to be able to directly measure engineering strains applied to the sample from crosshead displacement. This is an issue because a regular extensometer is too big for the gauge length of the in-situ test sample geometry.

\section{Conclusions}

- The present study has demonstrated a room temperature in-situ testing methodology on a nickel-based superalloy that produced EBSD mapping and SEM imaging during the test. Moreover, the acquisition of secondary electron images during testing provided a good resolution of slip system activation observations to be compared with calculated slip traces from raw EBSD data. 
- It was clear from in-situ observation that differently oriented grains deformed independently. However, they are largely affected by the surrounding neighbouring grains that caused different GND accumulation and sub-grain and orientation spread formation in various locations within the grains.

- It was found that the soft grains, high Schmid factor, can deform easily and accumulate GNDs only near the grain boundary under neighbouring grain influence. On the other hand, the "hard" grains which are not favourably orientated for slip system activation tend to reorientate upon loading to activate a possible octahedral slip system. Thus, they accommodate high GND density in the centre of the grains leading to grain fragmentation at the late stage of deformation under the influence of their orientation.

- The individual texture component area fraction changes during loading were dependant of their stability and simple shear condition during in-situ testing. This created large strain incompatibilities between neighbouring grains.

- The texture fibres were analysed during testing and it was concluded that $\langle 100\rangle / / \mathrm{X}$-axis with $<111>/ / \mathrm{X}$-axis increased and $<110>/ / \mathrm{X}$-axis decreased with increasing strain $\%$.

- It was evidence that carbide on the grain boundaries have a significant influence on slip transfer, slip direction changes and void formation between neighbouring grains. Whereas $\gamma^{\prime}$ precipitates had a negligible effect on slip direction changes within individual grains and slip transfer between neighbouring grains.

\section{Acknowledgements}

The authors of this paper would like to acknowledge the Materials and Manufacturing Academy (M2A) funding from the European Social Fund via the Welsh Government (C80816), the Advanced Imaging of Materials (AIM) facility (EPSRC Grant No. EP/M028267/1) and Rolls-Royce Plc for the 
provision of the material that has made this research possible. Special thanks to Dr. Liu Gang for his assistance in creating GND and slip traces maps.

\section{References}

[1] The Jet Engine, published by Rolls-Royce Plc, $5^{\text {th }}$ Edition, John Wiley and Son Ltd, Chichester, UK (1995).

[2] H. I. H Saravanamuttoo, G. F. C Rogers, H. Cohen, P. Straznicky, Gas Turbine Theory, $6^{\text {th }}$ Edition, Pearson Education Limited, Dorset, UK (2009).

[3] R. C. Reed, The Superalloys: Fundamentals and Applications. Cambridge University Press, Cambridge (2006).

[4] G. Veerappan, M. Ravichandran and S. Marichamy. Mechanical Properties and Machinability of Waspaloy for Aerospace Applications - Review. 2018 IOP Conf. Ser: Mater. Sci. Eng. 402, 012039, (2018)

[5] Tresa M. Pollock and Sammy Tin. Nickel-based superalloys for advanced turbine engines: chemistry, microstructure, and properties. Journal of propulsion and power. Vol. 22, No. 2. 361674. (2006)

[6] H. J. Stone, T. M. Holden and R. C. Reed - On the generation of micro strains during the plastic deformation of Waspaloy. Acta mater. Vol. 47, No. 17, pp. 4435-4448, (1999)

[7] Superalloys: A technical guide. S.J.Donachie, M.J.Donachie. s.I. : ASM International, 2002.

[8] I.A. Choudhury, M.A. El-Baradie. Machinability of nickel-base superalloys: a general review, J. Mater. Process. Technol. 77, 278-284. (1998)

[9] K-M Chang and X Liu. Effect of $\gamma^{\prime}$ content on the mechanical behaviour of the Waspaloy alloy system, J. Mater. Sci. Eng. A. 308, 1-8. (2001)

[10] W.P. Rehrer, D.R. Muzyka and G.B. Heydt. Solution Treatment and Al+Ti Effects on the Structure and Tensile Properties of Waspaloy JOM. 22, 32-38, (1970) 
[11] S. Birosca, G. Liu, M. Whittaker, R. Ding, J. Jiang, T. Simm, C. Dean. The dislocation behaviour and GND development in a nickel-based superalloy during creep. International Journal of Plasticity. 118, 252-268, (2019)

[12] Z. Yao, M. Zhang, J. Dong. Stress Rupture Fracture Model and Microstructure Evolution for Waspaloy. 44, 3084-3098. (2013)

[13] J. Busby: Metall. Met. Form., pp. 325-28. 1972

[14] R.J. Mitchel, Mark Hardy, Michael Preuss, Sammy Tin. Development of $\gamma^{\prime}$ morphology in P/M rotor disc alloys during heat treatment. Superalloys. 361-370, (2004)

[15] Carry C, Strudel JL. Apparent and effective creep parameters in single crystals of a nickelbased superalloy, Part II - secondary creep. Acta Metall, 26: 859-70, (1978)

[16] P. Nash, M.F. Singleton and J.L. Murray: Al-Ni Phase Diagrams of Binary Nickel Alloys. ASM International, pp 3-11 (1991).

[17] H.Y Li, J.F. Sun, M.C. Hardy, H.E. Evans, S.J. Williams, T.J.A. Doel and P. Bowen. The effect of microstructure on high temperature intergranular crack growth in nickel-base superalloys for disc applications. Acta Materialia, 90, 355-369, (2015)

[18] L. A. I. Kestens and H. Pirgazi (2016) Texture formation in metal alloys with cubic crystal structures, Materials Science and Technology, 32:13, 1303-1315, (2016)

[19] S. Birosca, F. Di. Gioacchino, S. Stekovic, M. Hardy (2014) A quantitative approach to study the effect of local texture and heterogeneous plastic strain on the deformation micromechanism in RR1000 nickel-based superalloy. Acta Materialia 74, 110-124, (2014)

[20] C. Rudolf, B. Boesl and A. Agarwal. - In Situ Mechanical Testing Techniques for Real-Time Materials Deformation Characterization. JOM, 66, 1, (2015)

[21] M.A. Tschopp, B.B. Bartha, W.J. Porter, P.T. Murray, and S.B. Fairchild. MicrostructureDependent Local Strain Behaviour in Polycrystals through In-Situ Scanning Electron Microscope Tensile Experiments. JOM and ASM International, 40, 2363-2368, (2009) 
[22] D. Raabe, Z. Zhao, S.J. Park, F. Roters. Theory of orientation gradients in plastically strained crystals/ Acta Materialia. 50. 421-440. (2002)

[23] A. Clair, M. Foucalut, O. Calonne, Y. Lacroute, L. Markey, M. Salazar, V. Vignal and E. Finot Strain mapping near triple junction in strain Ni-based alloy using EBSD and biaxial nano gauges. Acta Materialia, 59, 8, 3116-3123 (2011)

[24] A.J. Wilkinson. Deformation Textures. Encyclopaedia of Materials Science: Science and Technology (2nd edition). 2022-2026 (2001)

[25] E. Demir, D. Raabe, N. Zaafarani and S. Zaefferer. Investigation of the indentation size effect through the measurement of the geometrically necessary dislocations beneath small indents of different depths using EBSD tomography. Acta Materialia, 57, 2, 559-569 (2009)

[26] S. Birosca. The deformation behaviour of hard and soft grains in RR1000 nickel-based superalloy. IOP Conf. Ser.: Mater. Sci. Eng. 82. 012033 (2015)

\section{Figure Captions}

Figure 1: (a) SWF 5000 in-situ testing frame used in the current study with in-situ test piece fitted in the jaws. (b) The geometry and dimensions of the Waspaloy specimen used.

Figure 2: (a) Original microstructure of Waspaloy, (b) Gamma prime morphology of Waspaloy.

Figure 3: FEG-SEM-EDX chemical element maps confirming $\mathrm{Cr}_{23} \mathrm{C}_{6}$ carbides residing on the grain boundaries and high Ti concentration within the $\gamma^{\prime}$ precipitates.

Figure 4: Stress (MPa) Vs Crosshead displacement strain (\%) of Waspaloy at RT. 
Figure 5: (a1-a5) SEM FSE images of Waspaloy during in-situ tensile test. (b1-b5) (111) <1-10>// Xaxis Schmid factor, (c1-c5) Internal grain strain, (d1-d5) Local misorientation maps, (e1-e5) GND density evolution during tensile test. (1) pre-loading, (2) 600, (3) 1200, (4) 1800 and (5) 2400 crosshead displacement $(\mu \mathrm{m})$.

Figure 6: The texture component area fraction evolution during tensile test for (a1-a5) Cube $(001)<100>$, (b1-b5) Goss $(110)<100>,(c 1-c 5)$ Brass $(011)<211>$, (d1-d5) Copper $(112)<111>$ and (e1-e5) S (123)<634>. (1) pre-loading, (2) 600, (3) 1200, (4) 1800 and (5) 2400 crosshead displacement $(\mu \mathrm{m})$.

Figure 7: (a) Texture component area fraction evolution during in-situ tensile test, (b) Texture component area fraction difference during in-situ tensile test from $0-20.4 \%$ CHD strain (\%).

Figure 8: (a1-a5) Low angle grain boundary $(L A G B)<10^{\circ}$ evolution, (b1-b5) High angle grain boundaries $(H A G B)>15^{\circ}$ during tensile test. $(c 1-c 5)<100>/ / x$ texture fibre evolution. (d1-d5) $<110>/ / x$ texture fibre evolution. (e1-e5) <111>//x texture fibre evolution. (1) pre-loading, (2) 600, (3) 1200, (4) 1800 and (5) 2400 crosshead displacement ( $\mu \mathrm{m})$.

Figure 9: (a) (a) SEM image at $10.4 \%$ crosshead displacement strain with calculated slip trace showing good correlation with the real (111) <1-10> slip system activated. (b) IPF// ND map, (c) Schmid factor map // X-axis for the same area in (a).

Figure 10: (a) Backscatter (BS) SEM image showing slip system activation in different oriented grains, (b) magnified area of carbide rich grain boundary between a soft and hard grain, (c) magnified area of relatively carbide free grain boundary between a hard and a soft grain, (d) 
magnified area of carbide free grain boundary between 2 soft grain showing no sign of slip diversion and easy slip transfer.

Figure 11: Backscatter (BS) SEM images showing (a) the effect of $\gamma^{\prime}$ on the slip transfer, (b) the effect of carbide on slip transfer, (c) carbide effect on slip diversion and (d) the effect of strain incompatibility between multi grains and carbide presence of void formation at the triple junction.

\section{Table Captions:}

Table 1: Chemical composition of Waspaloy (wt\%).

Table 2: Statistical analysis of texture components area fraction evolution during tensile test.

Table 3: Statistical analysis of grains, texture components exhibited, $(111)<1-10>/ / X$-axis Schmid factor and Octahedral slip systems activated for the grains in Figure 9. 
Figures

Fig. 1
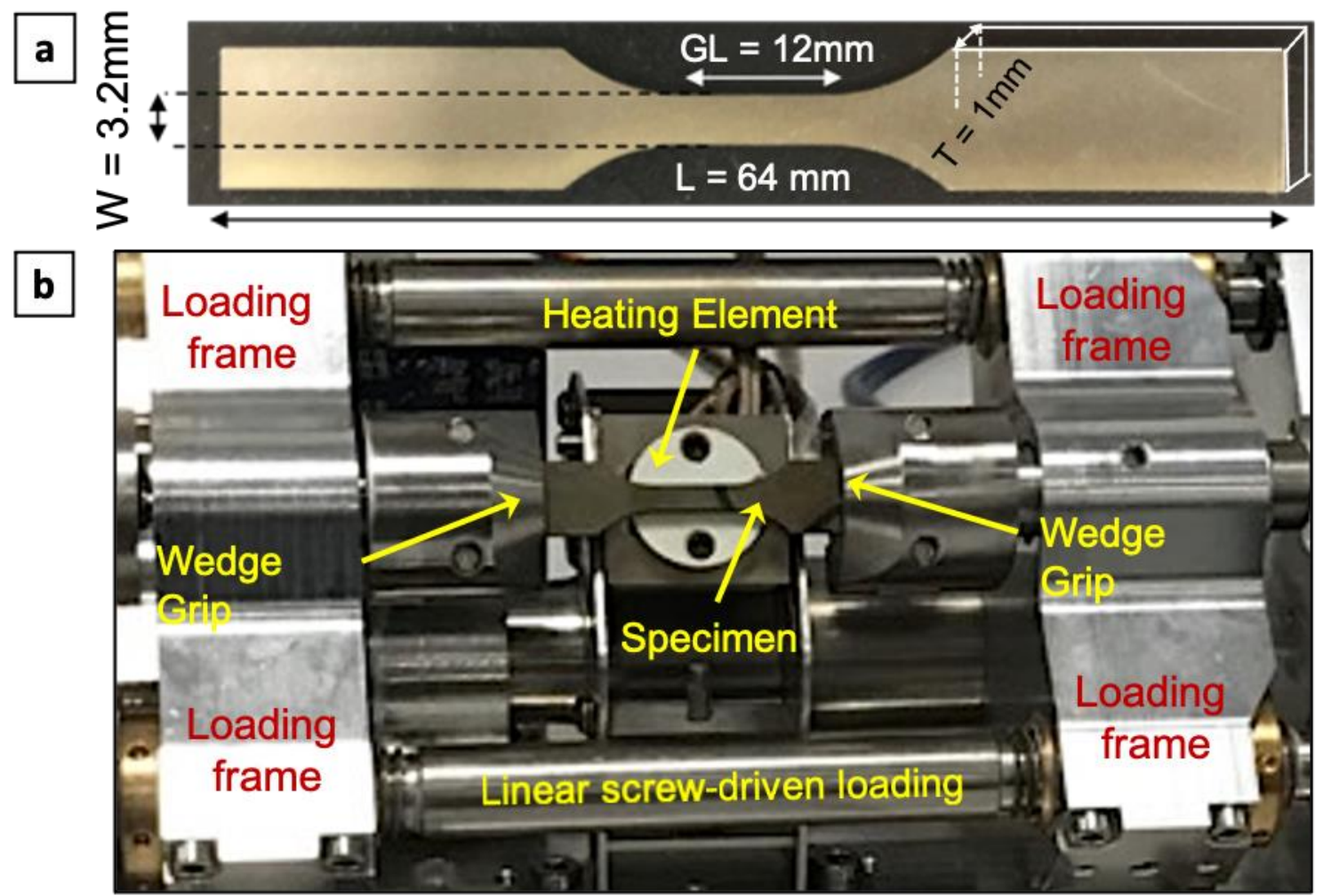

Fig. 2
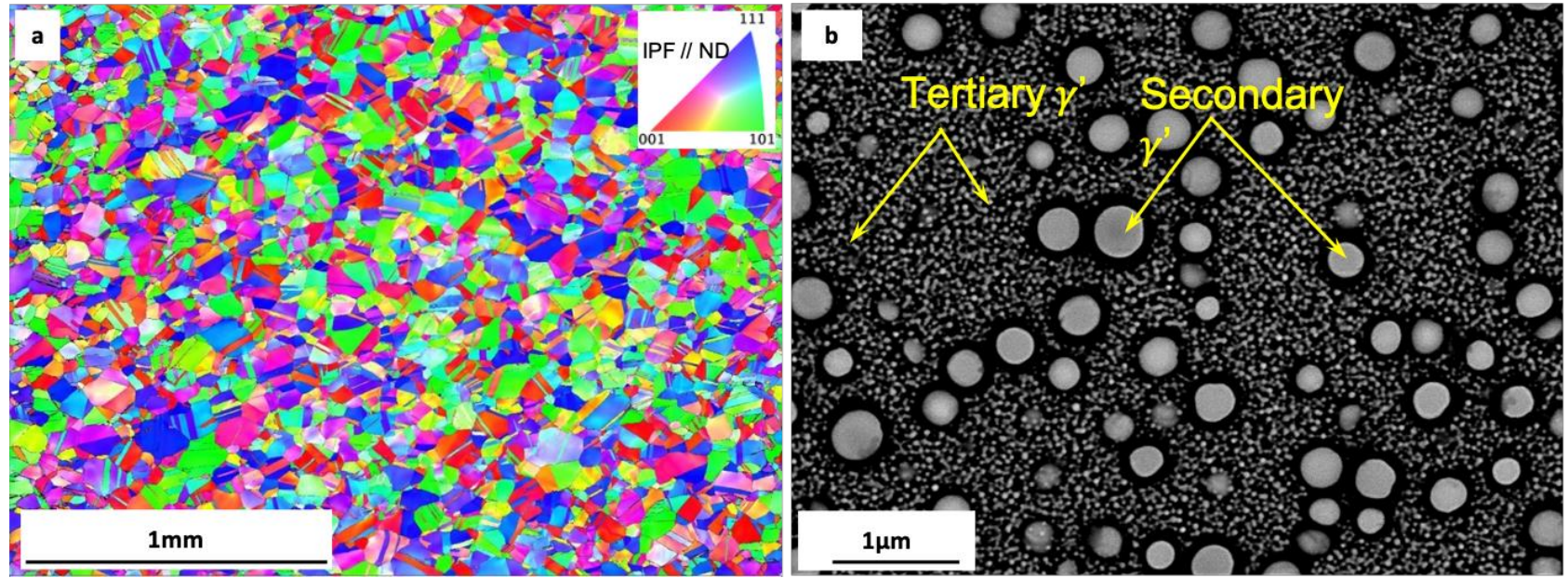
Fig. 3

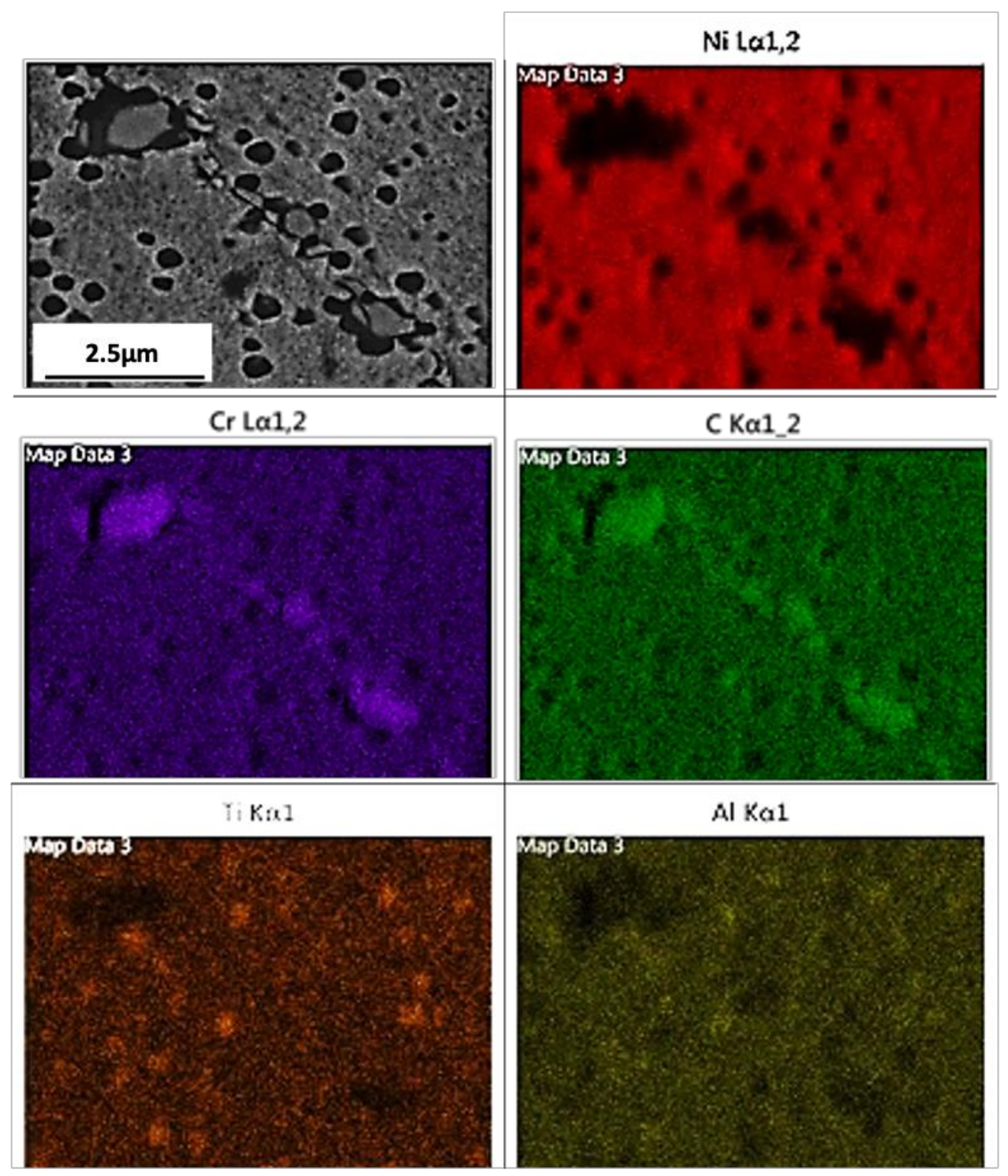


Fig. 4

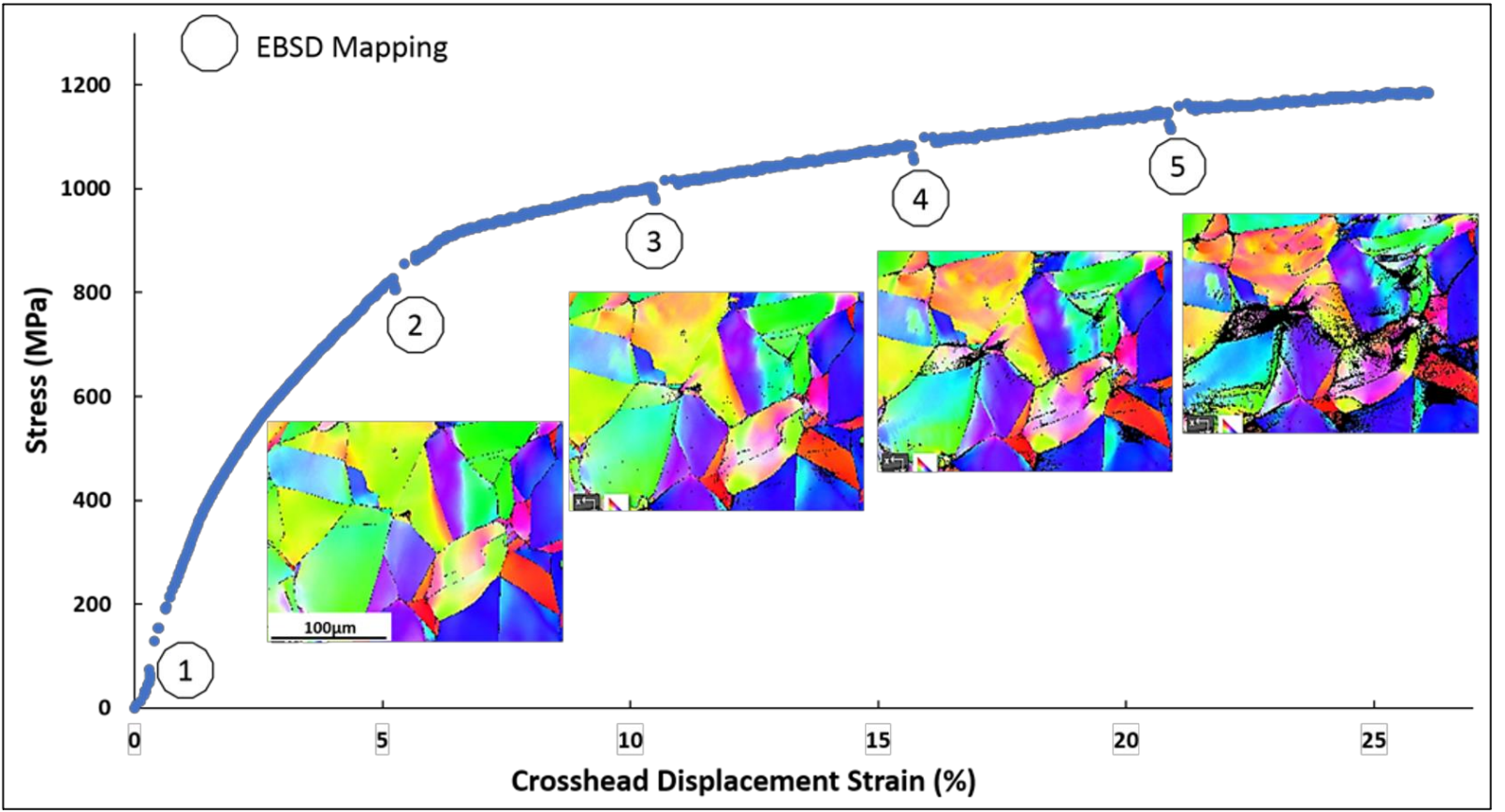

Fig. 5

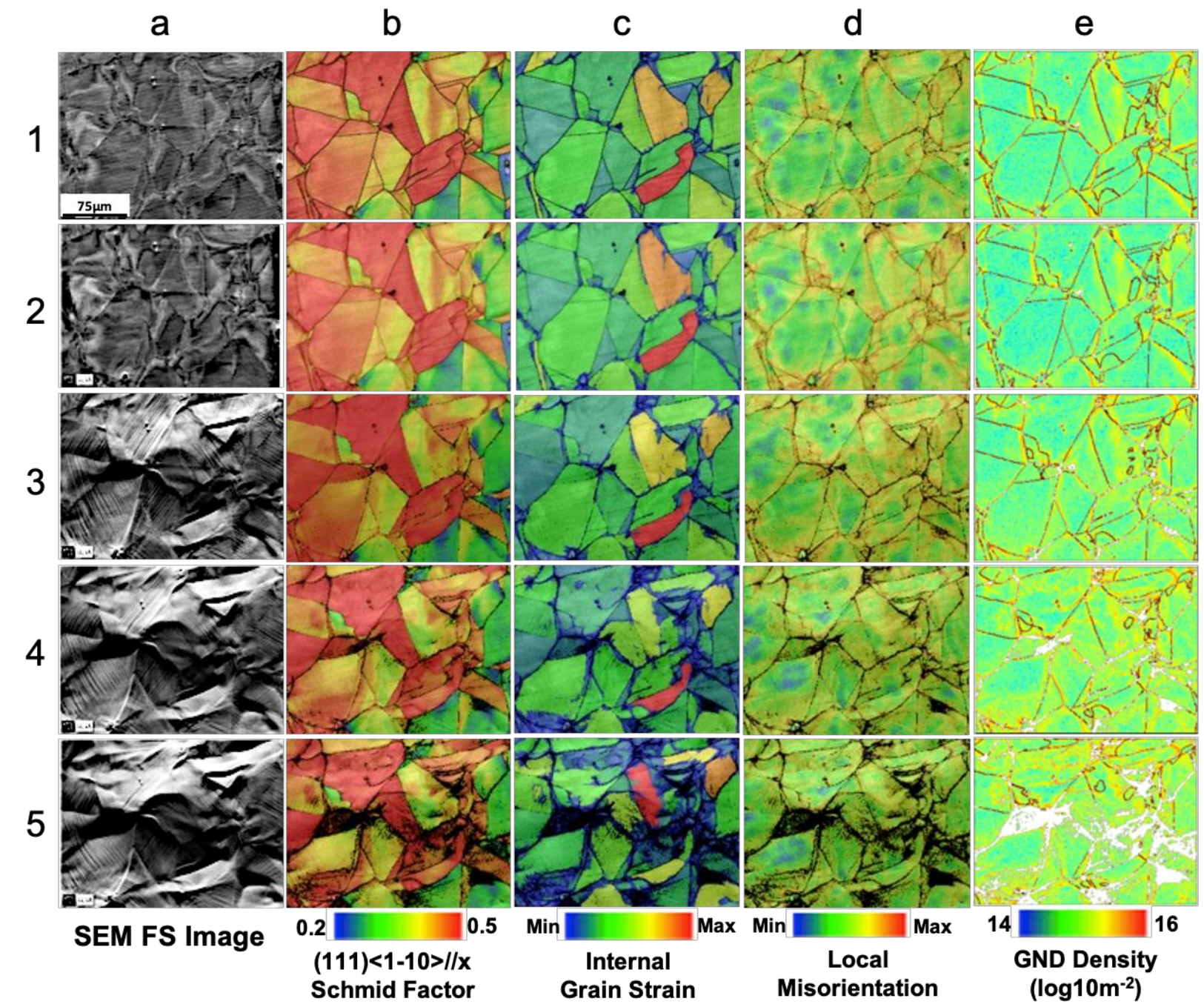


Fig. 6

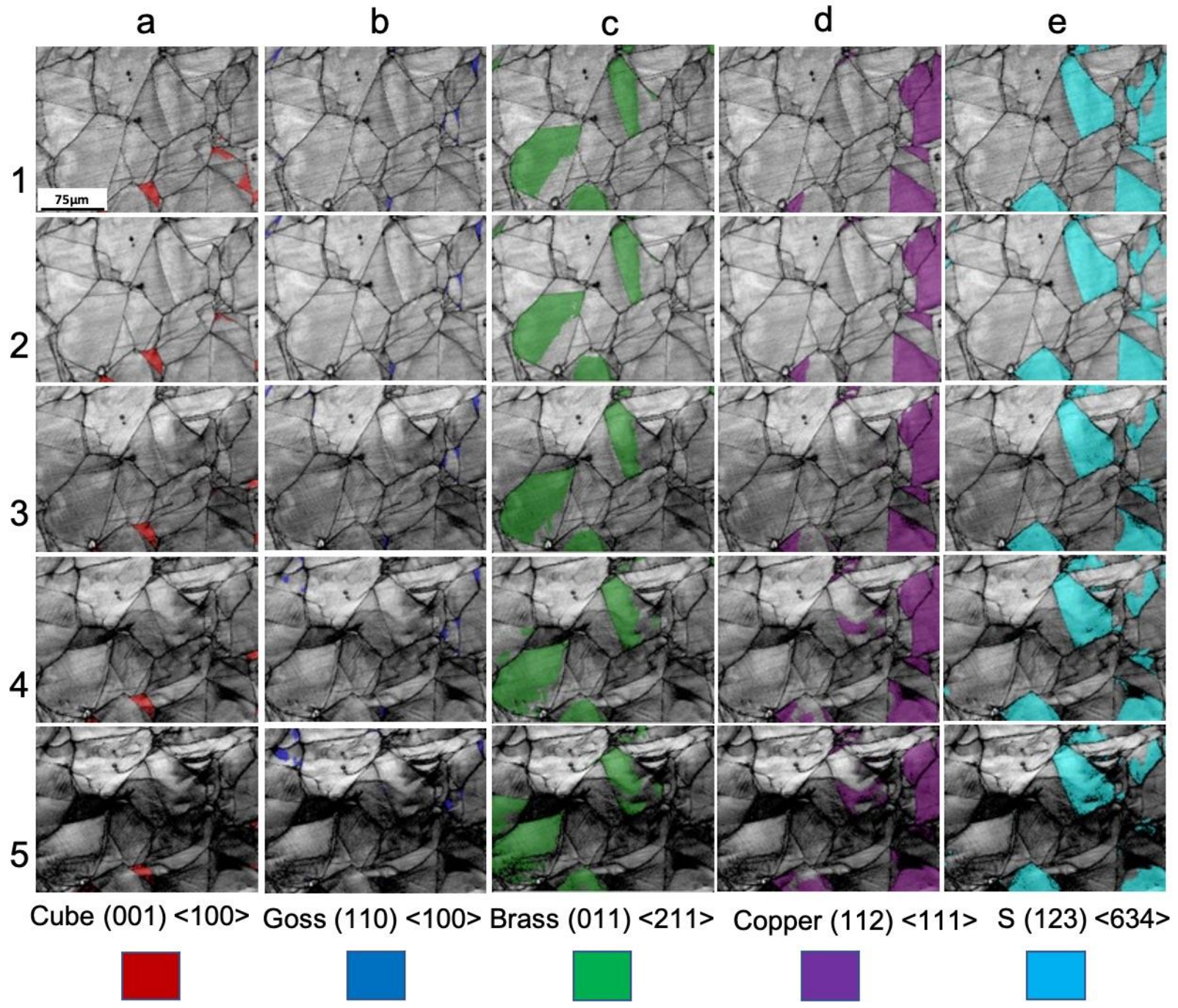

Fig. 7
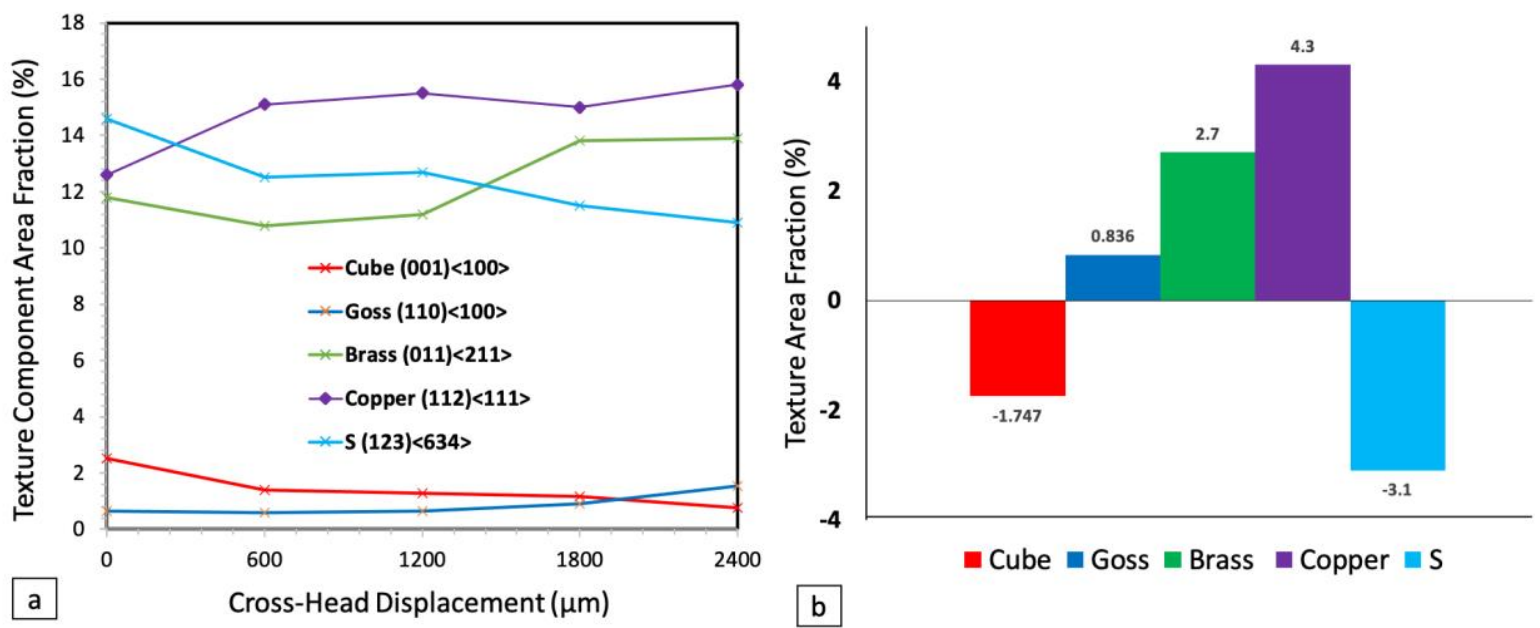
Fig. 8

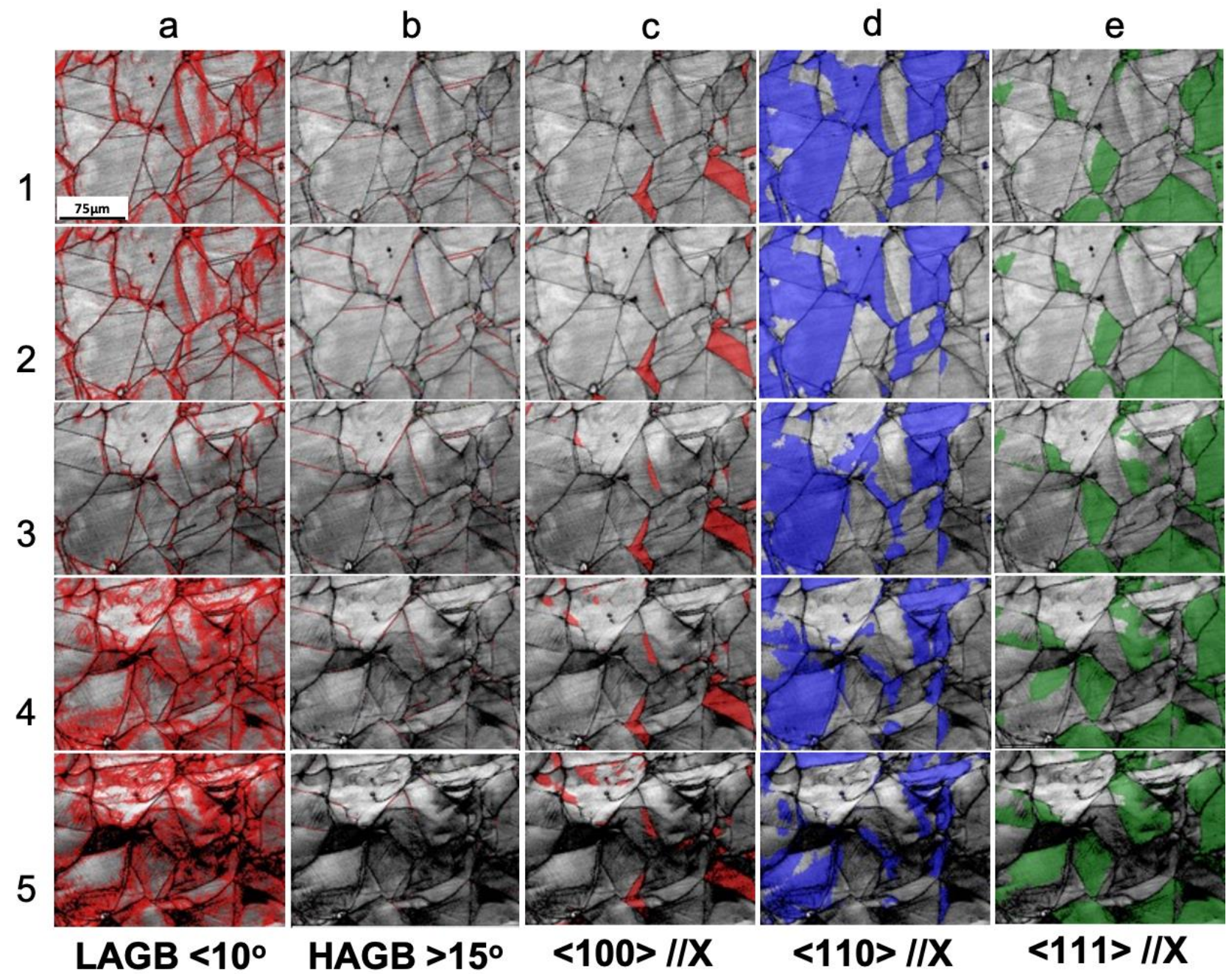


Fig. 9
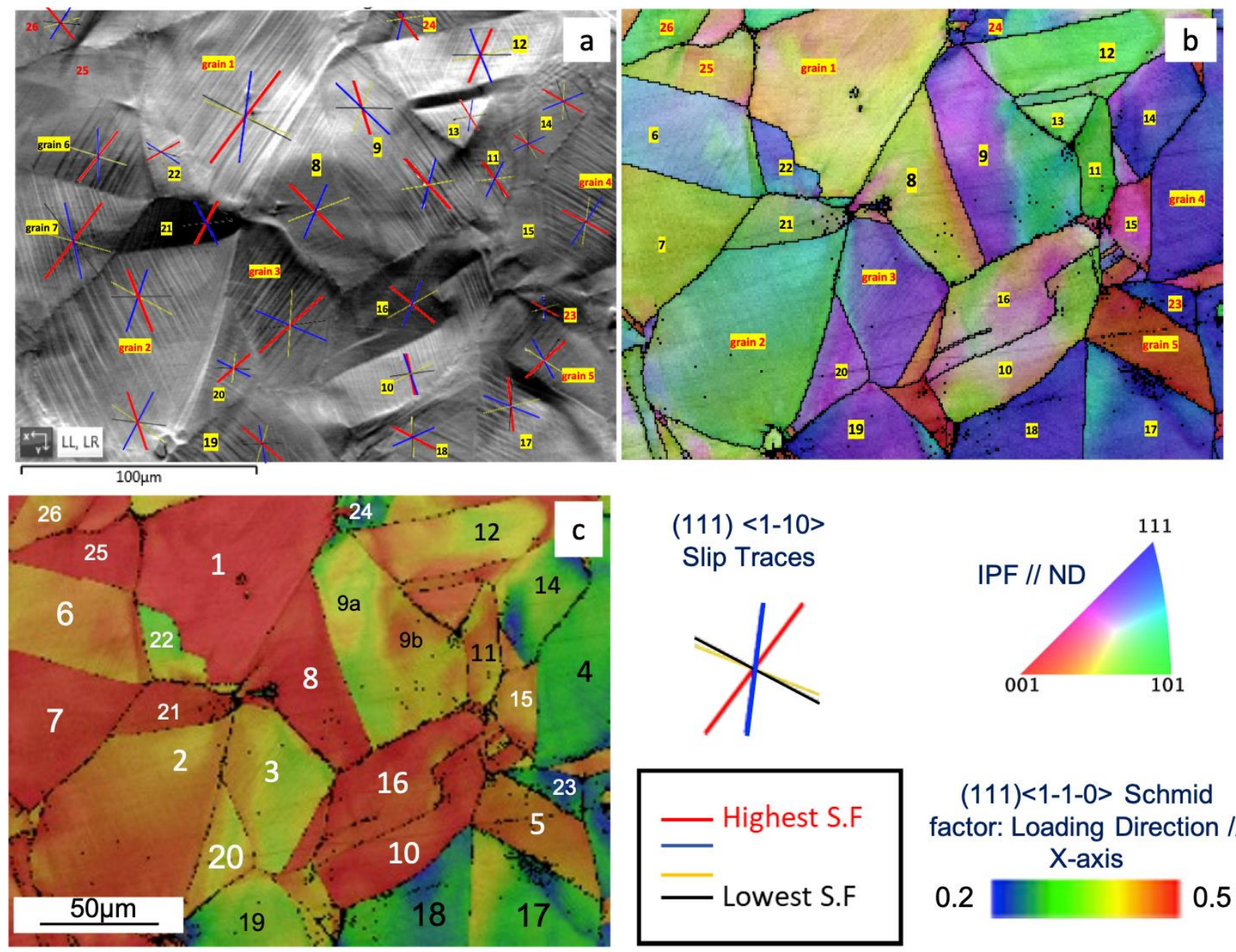

(111) <1-10>

Slip Traces
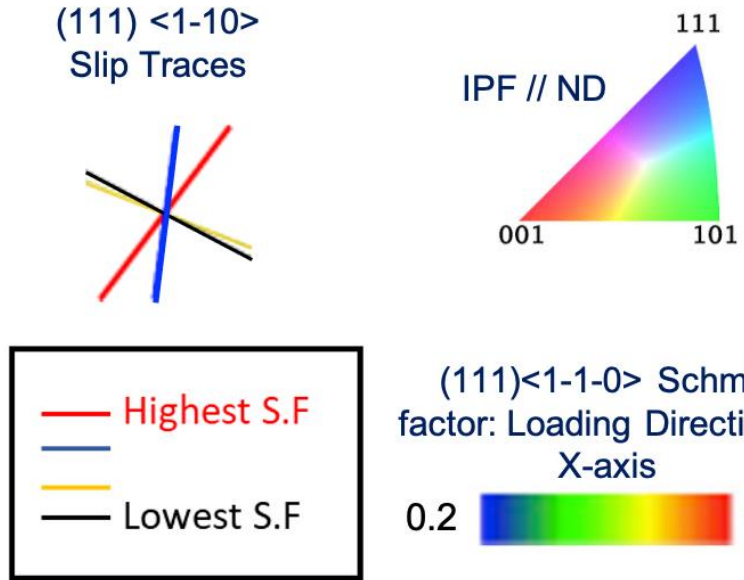

(111) $<1-1-0>$ Schmid factor: Loading Direction // $\mathrm{X}$-axis

0.2

0.5 
Fig. 10
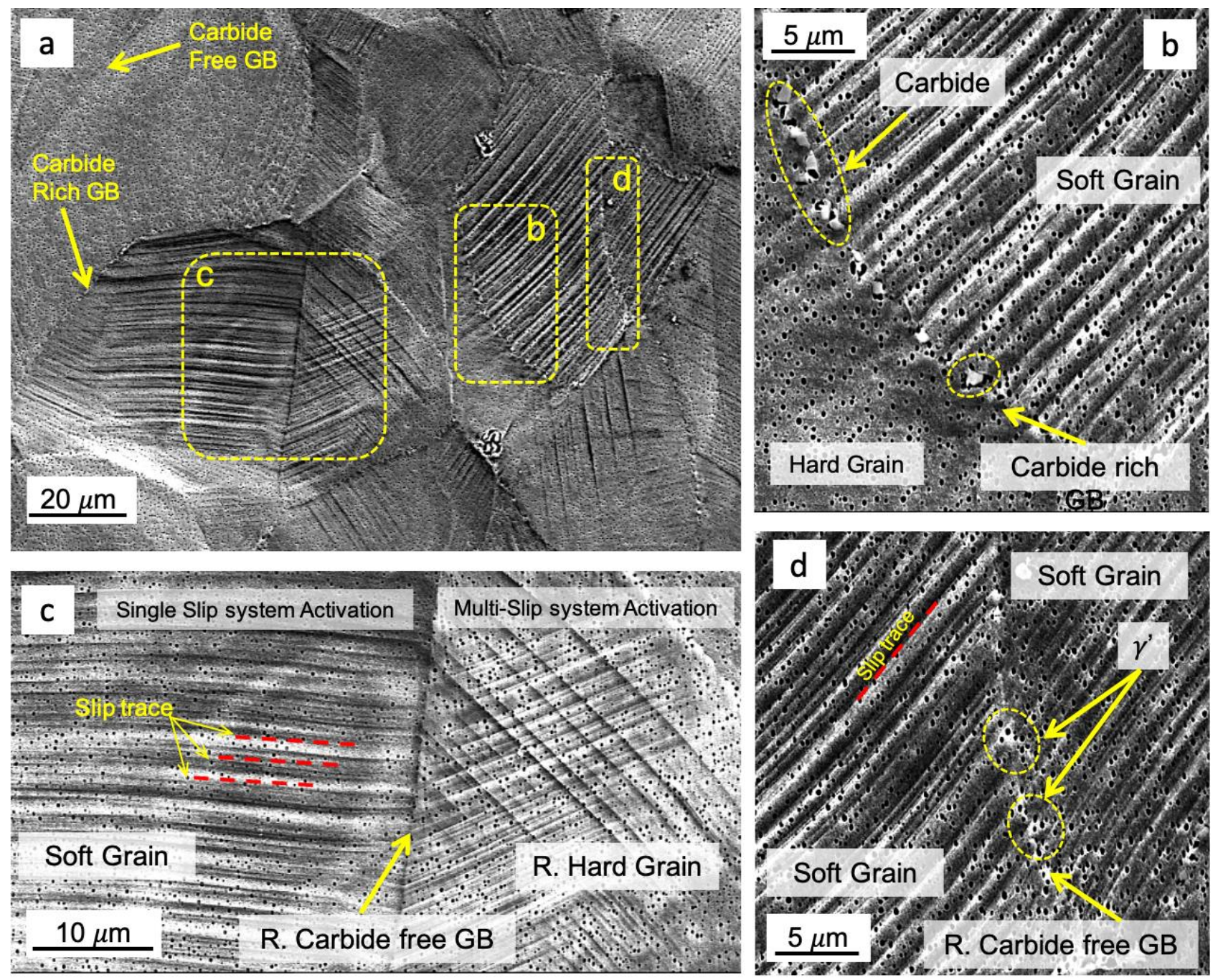
Fig. 11
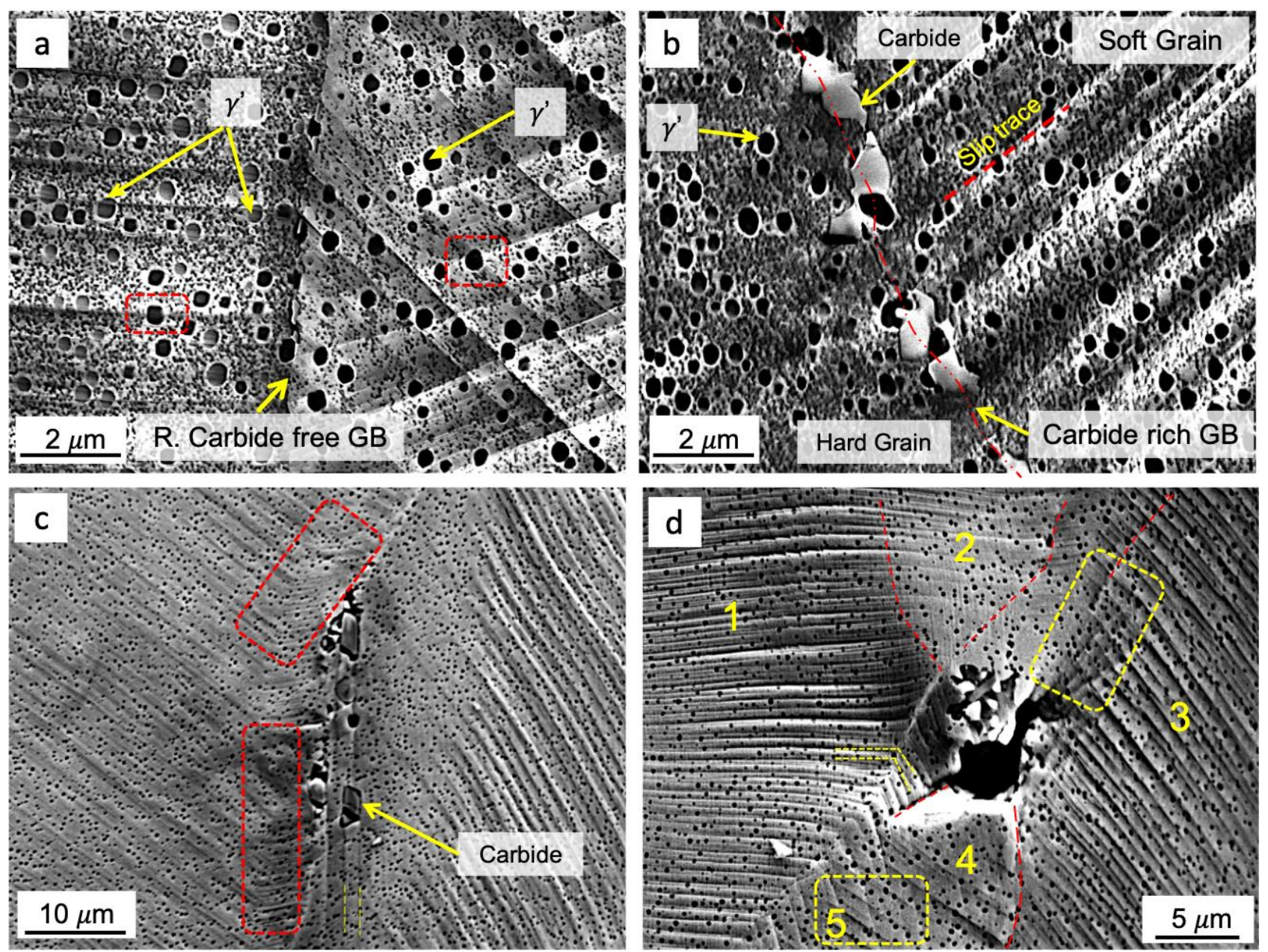
Tables:

Table 1

\begin{tabular}{cccccccccc}
\hline & $\mathrm{Ni}$ & $\mathrm{Cr}$ & $\mathrm{Co}$ & $\mathrm{Mo}$ & $\mathrm{Ti}$ & $\mathrm{Al}$ & $\mathrm{C}$ & $\mathrm{B}$ & $\mathrm{Zr}$ \\
\hline \% w/w max. & Bal & 21 & 15 & 5 & 3.25 & 1.6 & 0.1 & 0.01 & 0.08 \\
\hline
\end{tabular}

Table 2

\begin{tabular}{|c|c|c|c|c|c|}
\hline CHD Strain (\%) & Cube (001)<100> & Goss (011)<100> & Brass (011)<211> & Copper (112)<111> & S (123)<634> \\
\hline 0 & 2.51 & 0.714 & 19 & 17.5 & 23.9 \\
\hline 5.2 & 1.4 & 0.677 & 18.5 & 17.7 & 23.1 \\
\hline 10.4 & 1.27 & 0.647 & 19.4 & 18.6 & 22 \\
\hline 15.7 & 1.16 & 0.909 & 21 & 19.5 & 21.5 \\
\hline 20.9 & 0.763 & 1.55 & 21.7 & 21.8 & 20.8 \\
\hline A $_{F}$ Change (\%) & $\mathbf{- 1 . 7 4 7}$ & $\mathbf{0 . 8 3 6}$ & $\mathbf{2 . 7}$ & $\mathbf{4 . 3}$ & $-\mathbf{3 . 1}$ \\
\hline
\end{tabular}

Table 3

\begin{tabular}{|c|c|c|c|}
\hline Grain ID & Texture Component & $\begin{array}{c}\text { Schmid Factor } \\
(111)<110>/ / \mathbf{x}\end{array}$ & Slip System Activated \\
\hline 2 & Brass & 0.4 & $(-111)+(11-1)$ \\
\hline 4 & Copper & 0.36 & $(1-11)$ \\
\hline 5 & Part Cube & 0.46 & $(11-1)$ \\
\hline 7 & Rotates to Brass & 0.49 & $(-111)$ \\
\hline 9 above & Brass & 0.41 & $(1-11)$ \\
\hline 9 below & S & 0.42 & $(1-11)$ \\
\hline 14 & Copper & $0.36+0.32$ & $(1-11)+(-111)$ \\
\hline 15 & Part Goss & 0.45 & No Deformation \\
\hline 17 & Copper $+S$ & $0.37+0.26$ & $(111)+(1-11)$ \\
\hline 19 & Brass $+S$ & $0.41+0.39$ & $(1-11)+(-111)$ \\
\hline 20 & Cube & 0.43 & $(1-11)$ \\
\hline 23 & Copper $+S$ & 0.32 & $(1-11)$ \\
\hline 24 & Brass & 0.4 & $(1-11)+(11-1)$ \\
\hline 26 & Rotated Goss & $0.46+0.43$ & \\
\hline
\end{tabular}

